\title{
Why an open access journal in business librarianship?
}

\section{AMBER LANNON}

McGill University, Montreal, Quebec, Canada

Business librarians are a tight-knit group. Maybe it's because of the specialized knowledge that we are required to develop but rarely come to the job with in the first place. Or perhaps it's because of the crowded and complex vendor and product landscape we navigate daily. Whatever the reason, we have a long history of reaching out to the business librarian community to ensure our students, faculty, and patrons have access to the information they need in a timely way. We do this by forming networks (formal and informal) and by sharing information broadly and frequently through discussion lists, blogs, and at conferences. The professional relationships I have made with other business librarians are one of the most satisfying aspects of my career.

As professionals who support a discipline that is changing constantly, we also tend to be a group that embraces innovation and new ideas. Thus, it was no surprise to me that when I pitched the idea of starting a new journal in business librarianship, there was no shortage of collaborators ready to join in.

Every aspect of the work of a business librarian is moving quickly, as is the teaching and research of the faculty, students, and patrons we support. Business librarians have an urgent need for the most current information. That is why our aim is that Ticker, like a stock ticker, will be continuously updated with new information. To that end we will review and publish author submissions as they are received and reviewed.

Ticker also aims to support open, unrestricted access to information, on the principle that making research freely available supports a greater global exchange of knowledge. We will not be charging authors an article processing charge nor will we require them to hand over copyright of their work. While the journal is published and peer edited by the Academic Business Library Directors, we welcome submission from all librarians who have something to contribute.

Ticker is all about a commitment to sharing what we know and what we're learning in order to create new value propositions in our ever evolving library and information centres. It's a place to test ideas and get feedback and advice on whether to pivot or persevere. The success of Ticker depends on you, the global business librarian community, and so we challenge you to send us your ideas in the form of research articles, opinion pieces, case studies, and more. Visit ticker.mcgill.ca for more details.

Amber Lannon is the head of the Humanities and Social Sciences Library at McGill University; e-mail amber.lannon@mcgill.ca. 